\title{
Evaluation of Potential Drug Interaction of Analgesic in Cancer Patient Receiving Palliative Care in Dharmais Cancer Hospital
}

\author{
Eme Stepani Sitepu*, Atika Wahyu Puspitasari, Nuriza Ulul Azmi, Lila Nilam Sari \\ Faculty of Pharmacy, Universitas Indonesia, Depok, Indonesia
}

\begin{abstract}
Analgesics are mostly used in cancer patients receiving palliative care to improve the quality of life of patients. Besides analgesics, cancer patients receiving palliative care were also given other drugs in combination to overcome other symptoms of cancer, and this combination could potentially cause drug interactions. This study was aimed to analyze the potential of drug interactions with analgesics in cancer patients. The study design was cross-sectional with a retrospective method and descriptive study. The sample of this study was cancer palliative care patient's prescription at Dharmais Cancer Hospital in the period of January - December 2017. The sample analyzed in this study consisted of 273 prescriptions. This study found that there were 191 prescriptions $(69.9 \%)$ of analgesics which potentially interacted with 316 interaction cases. Fentanyl and morphine with 61 cases (19.3\%), morphine and gabapentin with 60 cases (18.9\%) and morphine and amitriptyline with 33 cases $(10.4 \%)$ were observed as the three most analgesics-other drugs interaction. Based on severity levels, there were $73.5 \%$ of major interaction, $26.3 \%$ of moderate interaction, and $0.2 \%$ of minor interaction. This study concluded that high occurrence of drug interactions was observed in analgesic drugs, therefore close monitoring is needed in cancer patient receiving palliative care.
\end{abstract}

ARTICLE HISTORY

Received: August 2019

Revised: February 2020

Accepted : April 2020

Keywords: drug interaction; analgesic; palliative care; cancer

*corresponding author

Email: emesitepu@farmasi.ui.ac.id

\section{INTRODUCTION}

Palliative care is an approach to improve the quality of life of patients and their families in coping with problems related to life-threatening diseases (WHO, 2014). Generally, palliative care is aimed not only to reduce the pain and other physical symptoms, but also to provide support psychosocially and spiritually to patients and their families during treatment and mourning time (Health Ministry of Indonesia, 2017). Palliative care is given to patients with these diseases, such as cardiovascular, cancer, chronic respiratory, HIV/ AIDS, diabetes, kidney, liver cirrhosis, tuberculosis medicine resistant, Parkinson, arthritis rheumatoid, and multiple sclerosis. However, the patient who needs palliative care the most after cardiovascular patient is cancer patient with the prevalence number of $34.01 \%$ (WHO, 2014).

Palliative care in cancer patients is usually given to manage symptoms like pain, psychiatric disorders, digestive system disorders, haematology disorders, and nervous system disorders (Health Ministry of Indonesia, 2017). The studies on breast and cervix cancer patients showed that the most prevalence of symptom that appeared in palliative care is a pain $(93.82 \%)$. Other symptoms are vomit $(26.40 \%)$, nausea $(23.03 \%)$, weight loss $(17.42 \%)$, cough $(7.87 \%)$, difficulty in breathing $(7.30 \%)$, fatigue $(4.49 \%)$, and lymphedema $(9.55 \%)$ (Elumelu et al., 2013).
The prevalence of pain becomes the highest in palliative care because most cancer patients have tumours pressing their organs, nerves, or bones that resulting in severe ache. Moreover, the pain is also caused by chemotherapy side effects, bad blood circulation, inflammation, and muscle cramps (Cancer Council Australia, 2015). That pain could be reduced by pharmacological therapy in a long duration of time, such as the administration of analgesic and adjuvant drugs. Besides analgesics, palliative patients are also given other drugs to manage other accompanying symptoms (Health Ministry of Indonesia, 2017), and this combination of drugs can potentially cause drug-drug interactions (Scott et al., 2013). The study by Leeuwen (2012) showed that there was a relationship between the numbers of drugs and the potential interaction of cancer drugs $(\mathrm{p}<0.0001)$.

Dharmais Cancer Hospital (RSKD) is a national cancer hospital and becomes the cancer reference center in Indonesia. As the cancer reference center, RSKD is functioned to give services, organize prevention and early detection activities, perform researches and to provide education (Panigoro, 2014). These functions encourage researchers to identify the potential drug interactions with analgesics in cancer patients receiving palliative care in this hospital. The purpose of this research is to analyze the types of analgesics, their interaction with other drugs, the severity levels and the proportion of interactions in the prescriptions of cancer patients receiving palliative care at RSKD. This study 
Table 1. Characteristic of the study sample

\begin{tabular}{lll}
\hline Characteristic of Sample & Number & Percentage (\%) \\
\hline Sex & & \\
Female & 187 & 68.5 \\
Male & 86 & 31.5 \\
\hline & & \\
Age (years) & & \\
Adult $(25-45)$ & 38 & 13.9 \\
Elderly $(>45)$ & 235 & 86.1 \\
\hline
\end{tabular}

could be used as considerations in prescribing and treating cancer patients related to the drug interactions that occurred in cancer patients receiving palliative care at Dharmais Cancer Hospital.

\section{METHODS}

\section{Study Design}

The study was conducted using a descriptive crosssectional design. The data were collected retrospectively using the secondary data from the prescription forms of cancer patients receiving palliative care at Dharmais Cancer Hospital in 2017. This study was carried out at RKSD in Letnan Jendral S. Parman Street Kav 84 - 86, Slipi, Palmerah, West Jakarta. The study population is every single one prescription forms of cancer patients receiving palliative care at RSKD from January until December 2017. The sample collecting technique used was the total sampling method. The samples used were the prescription forms of cancer patients receiving palliative care who took combination of analgesic and other drugs at Dharmais Cancer Hospital in 2017 who fulfilled inclusion criteria. The inclusion criteria for this study are cancer patients over twenty-five years old who have prescribed two or more types of drugs, one of which is analgesics, whereas exclusion criterion is the patients who took chemotherapy treatments.

The study has received permitted and ethics committee has approved (No. 036/KEPK/III/2018). The secondary data was further collected from the prescription forms of cancer patients receiving palliative care in 2017. The prescription data was taken from RSKD information system which consists of names, genders, ages, types of drugs prescribed, and dosage information. The analysis of the drug interactions was carried out using Micromedex ${ }^{\circledR}$ application from Truven Health Analytic and recent literature study manually.

\section{RESULTS AND DISCUSSIONS}

The total population of this study was 738 prescriptions, however, only 273 prescriptions fulfilled the inclusion criteria. The characteristics of the research sample is shown in Table 1 . A number of $68.5 \%$ of the samples were female patients, while $31.5 \%$ were male. The female patients were more than male because of a distinctive response from each gender towards pain. Females tend to have lower pain resistance compared to males. The pain in female patients is associated with a decrease in estrogen levels. The estrogen levels in menopausal woman change to a very low level causing they are more susceptible to pain response. Hormone Replacement Therapy (HRT) is used to manage the pain caused by the concentration of the hormone. This condition was also shown by the amount of sample from elderly patients ( $>45$ years old) which resulted in $86.1 \%$. A bigger number of elderly patients with palliative care than adult patients because mostly elderly patients have more complex problems, such as physical problems affecting their abilities to do their daily activities independently, and mental problems making them feel panicked of their disease diagnosis. Therefore, the palliative care team(s) is needed to assist elderly patients and their families (Davies \& Higginson, 2014; Pieretti et al., 2016; Vincent \& Tracey, 2008).

\section{Prescription Pattern}

The analgesics description in the pain management of cancer patients receiving palliative care is presented in Table 2. The pain management of cancer patients receiving palliative care at RSKD uses the WHO Step Ladder. The most prescribed opioid analgesic during pain therapy was morphine $(25.6 \%)$ and fentanyl (17.3\%). According to WHO Ladder, morphine and fentanyl are given to patients with the highest pain scale (7-10). Opioid analgesia is given to cancer patients because $70-80 \%$ of cancer patients suffered from the middle until high pain levels. The pain occurs because of the effect of the tumours which press the patients' bones, nerves, and other body organs. Many of the international organizations reported that by using WHO Step Ladder properly, $90 \%$ of the pain therapy succeeded to reduce the level of pain suffered by the cancer patients. Giving morphine decrease the pain much better and this strong opioid is needed to relieve the unbearable pain. However, each patient may have different responses towards morphine, so that to accomplish the optimum result of analgesic effect, titration dosage of morphine is needed. Therefore, the use of morphine needs to be evaluated 
Table 2. The analgesics description in the pain management of cancer patients receiving palliative care

\begin{tabular}{lll}
\hline Classification of Drug & Number & Percentage (\%) \\
\hline Opioid Analgesic & & \\
Morphine & 150 & 25.6 \\
Fentanyl & 101 & 17.3 \\
Codeine & 5 & 0.8 \\
Tramadol & 3 & 0.5 \\
Hydromorphone & 3 & 0.5 \\
Oxycodone & 1 & 0.2 \\
Non Opioid Analgesic & & \\
Paracetamol & 94 & 16.1 \\
Ibuprofen & 18 & 3.1 \\
Ketoprofen & 3 & 0.5 \\
Aspirin & 1 & 0.2 \\
Parecoxib & 1 & 0.2 \\
Analgesic Adjuvant & & \\
Gabapentin & 94 & 16 \\
Amitriptyline & 52 & 8.9 \\
Hyoscine butylbromide & 17 & 2.9 \\
Valproic Acid & 4 & 0.7 \\
Pirasetam & 8 & 1.4 \\
Phenytoin & 2 & 0.3 \\
Alprazolam & 3 & 0.5 \\
Diazepam & 3 & 0.5 \\
Ibandronic Acid & 2 & 0.3 \\
Methylprednisolone & 2 & 0.3 \\
Dexamethasone & 15 & 2.6 \\
Budesonide & 3 & 0.5 \\
\hline & &
\end{tabular}

Table 3. Percentage of potential drug interaction on prescription

\begin{tabular}{lll}
\hline Potential Interaction & Number & Percentage (\%) \\
\hline Interacted & 191 & 69.9 \\
Not Interacted & 82 & 30.1 \\
\hline TOTAL & 273 & 100 \\
\hline
\end{tabular}

individually because each patient has a different dosage requirement. Observing patients towards morphine intake is performed during one until four weeks after the chronic pain therapy or the increased dosage began. Another type of analgesic is fentanyl. Along with the previous research on the international journal on clinical pharmacy, fentanyl was one of the most opioid analgesics prescribed during pain therapy after morphine. Fentanyl in patch form is needed by terminal cancer patients to decrease the pain in a certain period of time (Dowell, 2016; Jain P., Pai K., \& Chatterjee A., 2015; Health Ministry of Indonesia, 2017; Masman, 2015; Rana et al., 2011).

Meanwhile, the most prescribed nonopioid analgesic was paracetamol with a percentage of $16.1 \%$. It was aligned with WHO Step Ladder guidance which explains that paracetamol is given to the patient with the lowest pain level $(1-3)$. Paracetamol is usually preferred because of the lowest side effects compared to NSAIDs (Health Ministry of Indonesia, 2017; McClay, 2010).

The most commonly prescribed adjuvant drug for pain management in cancer patients receiving palliative care was gabapentin (16\%). Gabapentin is an analgesic acted on subunit alpha- $\delta$ voltage-gated calcium by increasing GABA synthetic (gamma-aminobutyric acid) which functioned as the neurotransmitter inhibitor on the central nervous system. Based on the completed case studies, adjuvant like gabapentin has been proved to support the action of opioid analgesics on cancer patients' management. The other adjuvant pain drug prescribed was amitriptyline (8.9\%). It is a tricyclic antidepressant known as a serotonin-norepinephrine reuptake inhibitor (SNRI) which is a neurotransmitter in pain modulation so that able to reduce the pain. Amitriptyline has also been proven to reduce pain for patients who suffer neuropathic pain. Gabapentin and 
Table 4. Data of potential analgesic and drug interaction based on severity level

\begin{tabular}{|c|c|c|}
\hline Drug Interaction & Incidence & Percentage $(\%)$ \\
\hline Major Interaction & & 73.5 \\
\hline \multicolumn{3}{|l|}{ Opioid Analgesic - Opioid Analgesic } \\
\hline Fentanyl - Morphine & 61 & 19.3 \\
\hline Codeine - Fentanyl & 4 & 1.3 \\
\hline Fentanyl - Tramadol & 1 & 0.3 \\
\hline Hydromorphone - Morphine & 1 & 0.3 \\
\hline Morphine - Tramadol & 1 & 0.3 \\
\hline \multicolumn{3}{|l|}{ Opioid Analgesic - Analgesic Adjuvant } \\
\hline Morphine - Amitriptyline & 33 & 1.4 \\
\hline Fentanyl - Amitriptyline & 4 & 1.3 \\
\hline Fentanyl - Alprazolam & 3 & 0.9 \\
\hline Morphine - Alprazolam & 2 & 0.6 \\
\hline Fentanyl - Dexamethasone & 2 & 0.6 \\
\hline Codeine - Dexamethasone & 1 & 0.3 \\
\hline \multicolumn{3}{|l|}{ Opioid Analgesic - Other drugs } \\
\hline Morphine - Ondansetron & 32 & 10.1 \\
\hline Fentanyl - Ondansetron & 22 & 6.9 \\
\hline Morphine - Metoclopramide & 19 & 6 \\
\hline Fentanyl - Metoclopramide & 13 & 4.1 \\
\hline Fentanyl - Ranitidine & 3 & 0.9 \\
\hline Tramadol - Ondansetron & 2 & 0.6 \\
\hline Fentanyl - Ciprofloxacin & 2 & 0.6 \\
\hline Morphine - Captopril & 1 & 0.3 \\
\hline Tramadol - Ciprofloxacin & 1 & 0.3 \\
\hline Hydromorphone - Metoclopramide & 1 & 0.3 \\
\hline Morphine - Chlorpeniramine Maleate & 1 & 0.3 \\
\hline Codeine - Ranitidine & 1 & 0.3 \\
\hline \multicolumn{3}{|l|}{ Non Opioid Analgesic - Analgesic Adjuvant } \\
\hline Ibuprofen - Amitriptyline & 4 & 1.3 \\
\hline \multicolumn{3}{|l|}{ Non Opioid Analgesic - Other drugs } \\
\hline Ibuprofen - Warfarin & 2 & 0.6 \\
\hline Ibuprofen - Rivaroxaban & 1 & 0.3 \\
\hline \multicolumn{3}{|l|}{ Analgesic Adjuvant - Analgesic Adjuvant } \\
\hline Diazepam - Phenytoin & 1 & 0.3 \\
\hline \multicolumn{3}{|l|}{ Analgesic Adjuvant - Other drugs } \\
\hline Amitriptyline - Ondansetron & 7 & 2.2 \\
\hline Amitriptyline - Ciprofloxacin & 1 & 0.3 \\
\hline Amitriptyline - Chlorpeniramine Maleate & 1 & 0.3 \\
\hline Amitriptyline - Metoclopramide & 4 & 1.3 \\
\hline Moderate Interaction & & 26.3 \\
\hline \multicolumn{3}{|l|}{ Opioid Analgesic - Analgesic Adjuvant } \\
\hline Morphine - Gabapentin & 60 & 18.9 \\
\hline \multicolumn{3}{|l|}{ Opioid Analgesic - Other drugs } \\
\hline Morphine - Furosemide & 4 & 1.3 \\
\hline \multicolumn{3}{|l|}{ Non Opioid Analgesic - Other drugs } \\
\hline Paracetamol - Warfarin & 3 & 0.9 \\
\hline Paracetamol - Phenytoin & 1 & 0.2 \\
\hline \multicolumn{3}{|l|}{ Analgesic Adjuvant - Other drugs } \\
\hline Gabapentin - Antacid & 6 & 1.9 \\
\hline Amitriptyline - Warfarin & 4 & 1.3 \\
\hline Alprazolam - Omeprazole & 1 & 0.2 \\
\hline Dexamethasone - Fluconazole & 1 & 0.2 \\
\hline Dexamethasone - Warfarin & 1 & 0.2 \\
\hline Dexamethasone - Aspirin & 1 & 0.2 \\
\hline Dexamethasone - Phenytoin & 1 & 0.2 \\
\hline Minor Interaction & & 0.2 \\
\hline \multicolumn{3}{|l|}{ Analgesic Adjuvant - Other drugs } \\
\hline Diazepam - Omeprazole & 1 & 0.2 \\
\hline TOTAL & 316 & 100 \\
\hline
\end{tabular}


amitriptyline are neuropathic analgesics prescribed at Dharmais Cancer Hospital, so these drugs are used as an adjuvant in the pain therapy at RSKD (Dawson, 2014; RSKD Pharmacy and Therapy Committee, 2017; Moore, 2015; Rana, 2011; Su, 2015).

\section{Drug Interactions}

The drug interactions from 273 prescriptions fulfilled inclusion criteria were analyzed based on the severity level using Micromedex Drug Interaction Checker. As shown in Table 3, 191 out of 273 prescriptions (69.9\%) potentially had drug interactions. The analysis results of drug interactions with an analgesic are presented in Table 4 , it was found that 316 cases with the major severity level were $73.5 \%$, the moderate level was $26.3 \%$, and the minor level was $0.2 \%$.

The drug interactions with major severity level were mostly occurred on fentanyl and morphine combination, resulting in 61 cases $(19.3 \%)$. The interaction effects occurring between these two drugs are increasing respiratory depression, central nervous system, and serotonin syndrome risks. Fentanyl and morphine have a similar analgesic mechanism that impacts the central nervous system and serotonin concentration so that using these two drugs at the same time could increase the effect or have the synergistic effect (Kotlinska-Lemieszek, 2015). Fentanyl is prescribed based on the morphine dosage which needs time adjustment by twenty-four hours in advance. Fentanyl and morphine could be administered simultaneously by managing interval time of administration and using different dosage forms. The transdermal effect from fentanyl is reached maximally after twelve hours of intake. If the patient is prescribed oral morphine every four hours, it could be administered until twelve hours after transdermal fentanyl intake. Meanwhile, if the patient is given modified oral morphine every twenty-four hours, transdermal fentanyl could be given twelve hours after morphine dosage optimally reached (Kuczynska, 2017).

Morphine and gabapentin are the combinations of opioid and adjuvant drug which potentially cause moderate drug interactions. The drug interaction effect of combining morphine and gabapentin is increasing the plasma concentration of gabapentin due to pharmacokinetic changes. Therefore, the pharmacokinetic effect is the increase of gabapentin absorption, which is caused by the effect of morphine lowering the intestinal motility. This effect leads to longer gabapentin transit time in the intestine and resulting in the absorption of gabapentin more than needed and increasing the plasma concentration of gabapentin. The combination of these two drugs at the same time could increase the level of AUC gabapentin by $44.4 \%$ resulting in multiplying the side effects of gabapentin $(\mathrm{P}<0.05)$ (Feng et al., 2017). The therapy management of prescribing morphine and gabapentin at the same time could be carried out by giving morphine two hours before gabapentin administration so that the lowering intestinal motility has already happened before gabapentin is given (Chen et al., 2015).

Morphine and amitriptyline is the opioid analgesic and adjuvant drug. This combination has potential major severity in drug interactions. The drug interaction effect between morphine and amitriptyline is the increase in serotonin syndrome risks. Morphine is the opioid type with glucuronidase metabolism, while amitriptyline is the tricyclic antidepressant type (TCA) which is a noncompetitive glucuronidase inhibitor. Therefore, the combination could inhibit the metabolism of morphine. Based on the reports of the lung cancer patient with bone metastasis consuming both morphine and amitriptyline, amitriptyline was used not only to decrease incidental pain and contribute to cause a sedative effect but also to delay morphine clearance so that increase the serotonergic effect. The accumulated amitriptyline resulted from 24-hours half-life could increase the risk of drug interaction with morphine (Upadhyay, 2008). The administration of amitriptyline with morphine or the same type of analgesics is carried out by giving amitriptyline with a smaller dosage (The Christie NHS Foundation Trust, 2012).

Furthermore, the combination of morphine and ondansetron has a potential drug interaction with the effect of increasing the serotonin syndrome risk. Ondansetron is an antiemetic drug acted as a 5-HT3 receptor antagonist and associated with the serotonin concentration inside the body. Moreover, serotonin is known to increase the serotonergic activities, therefore, the administration of morphine and ondansetron at the same time could initiate the serotonin concentration to be higher and simultaneously make the serotonin syndrome happens. The serotonin syndrome is originated from the hyperstimulation of the 5-HT receptor causing mental status changes, conscious effects, autonomy dysfunctional, and neuromuscular abnormalities (Vizcaychipi, 2007). Therefore, monitoring the effects of the serotonin syndrome and giving the serotonin antagonist such as cyproheptadine and chlorpromazine are needed during the therapy management (Vizcaychipi, 2007). On the other hand, a combination of fentanyl and ondansetron also potentially cause major drug interaction with a similar effect, increasing the risk of serotonin syndrome. Ondansetron is an antiemetic with a 5-HT3 antagonist mechanism used in the serotonin syndrome precipitation. Fentanyl is a 5-HT1 antagonist adding more serotonin releases by using serotonin takes and serotonin intrasynaptic level increases. In the case study of fifty-eight years old male patient who received the pain therapy, he suffered from serotonin precipitation 
Table 5. Proportion of potential analgesic and drug interactions based on gender and age

\begin{tabular}{|c|c|c|c|c|c|c|}
\hline \multirow{2}{*}{\multicolumn{2}{|c|}{ Characteristic of Patient }} & \multirow{2}{*}{$\begin{array}{l}\text { Number of } \\
\text { Prescription }\end{array}$} & \multicolumn{2}{|c|}{$\begin{array}{l}\text { Prescription with } \\
\text { Potential Drug } \\
\text { Interactions }\end{array}$} & \multicolumn{2}{|c|}{$\begin{array}{l}\text { Prescription without } \\
\text { Potential Drug } \\
\text { Interactions }\end{array}$} \\
\hline & & & Number & $\begin{array}{l}\text { Percentage } \\
(\%)\end{array}$ & Number & $\begin{array}{l}\text { Percentage } \\
(\%)\end{array}$ \\
\hline \multirow{2}{*}{ Sex } & Male & 66 & 66 & 24.2 & 20 & 7.3 \\
\hline & Female & 125 & 125 & 45.8 & 62 & 22.7 \\
\hline \multirow{2}{*}{ Age } & Adult & 27 & 27 & 9.9 & 11 & 4 \\
\hline & Elderly & 164 & 164 & 60.1 & 71 & 26 \\
\hline
\end{tabular}

imbalance that increased the possibility of serotonin syndromes, like mental status changes, neuromuscular abnormalities, and autonomy instabilities (Rastogi, 2011). Therefore, the above therapy management was using nonserotonergic medicine, lowering the dosage, stoping the administration of the serotonergic agent (Rastogi, 2011).

Morphine and metoclopramide also potentially cause major drug interactions. The implication caused by these two drugs combined is the increased risk of central nervous system depression. Morphine is the MU selective receptor opioid with primary action in the central nervous system in the brain. Metoclopramide is the antiemetic medicine acted in two different mechanisms, in the central nervous system as an antagonist on dopamine D2 receptor and in the digestive system as a cholinergic agonist. In the previous researches, the administration of metoclopramide and morphine in patients undergoing surgeries significantly shortened Tmax of morphine, accelerated the onset, and improved the sedation, so that it impacted the central nervous system. The increase of morphine absorption is caused by metoclopramide effects which increase gastric emptying (Feng, et.al., 2017). The therapy management for this condition is decreasing dosage to reduce the potential effects from the administration of the gastrokinetic agent during analgesic opioid intake simultaneously (Feng et al., 2017).

The possibilities proportion of drug interactions with analgesics in cancer patients could be observed based on gender and age. Female patients' prescriptions are more likely to have drug interactions compared to male patient's prescriptions. On the other hand, elderly patient's prescriptions are more likely to have drug interactions compared to adult patients prescriptions. The data is presented in Table 5 .

The gender difference between males and females is associated with pharmacokinetic process causing the risks to happen. During the absorption process, the absorption speed is affected by the intestine transit time. Intestine transit time in males is lower than females and may result in drug interactions. Besides, body fat composition could affect the process during the distribution process. Body fat composition in males is lower than female so it might give an effect if the patient is prescribed with the combination of drugs has the potential to interact. Throughout the metabolism process, enzyme CYP3A4 and CYP2D6 activities in males are lower than females, thus it could influence the pharmacokinetic effect of the drug which is broken down by the enzymes (Soldin, 2009; Franconi and Campesi, 2014). Pharmacokinetic and pharmacodynamic changes inside the body often happen in conjunction with the aging process so the changes are considered as the risk factors of drug interactions. Pharmacokinetic changes happening in geriatric patients are body composition changes, liver function changes as a result of drug metabolism, kidney function changes as a result of drug excretion, and multi-pathology condition. Body composition changes as humans grow older, the older a human becomes, the lower body fluids get, on the contrary, the higher body fat gains. This condition could affect the distribution of drugs inside the body. As humans are getting aged, liver and kidney functions are also getting lowered as the result of the metabolism and excretion process of the drug. Meanwhile, the pharmacodynamic changes occurred in this process is the decrease of tissue sensitivity towards drug as a result of degenerated drug receptor in the tissue (Health Ministry of Indonesia, 2006; Delafuente, 2008; Turnheim, 2003).

\section{CONCLUSION}

This study showed that the most frequently prescribed analgesics to cancer patients receiving palliative care at Dharmais Cancer Hospital in 2017 are morphine (25.6\%). The percentage of drug interactions towards analgesics occurring in the prescriptions of cancer patients with palliative care at Dharmais Cancer Hospital in 2017 is $69.9 \%$. fentanyl and morphine with 61 cases $(19.3 \%)$, morphine and gabapentin with 60 
cases $(18.9 \%)$ and morphine and amitriptyline with 33 cases $(10.4 \%)$ were observed as analgesics with most drug interaction with other drugs. The severity levels on the drug interactions are major $(73.5 \%)$, moderate $(26.3 \%)$, and minor $(0.2 \%)$. Furthermore, the proportion of analgesic drug interactions in cancer patients with palliative care, based on gender and age category, were found more frequently in female groups $(65.4 \%)$ and the elderly group $(85.9 \%)$. Therefore for both groups, it is recommended to prescribe alternative combinations. If there is no alternative combination, close monitoring should be implemented.

\section{ACKNOWLEDGEMENT}

The authors would like to give their gratitude to Dharmais Cancer Hospital for the contribution.

\section{REFERENCES}

Chen, C., Upward, J., Arumugham, T., Stier, B., \& Davy, M. (2015). Gabapentin Enacarbil and Morphine Administered in Combination Versus Alone: A Doubleblind, Randomized, Pharmacokinetic, and Tolerability Comparison. Clinical Therapeutics, 37(2), 349-357. doi:10.1016/j.clinthera.2014.10.015.

Davies, E., \& Higginson, I. J. (2004). Better palliative care for older people. Copenhagen, Denmark: World Health Organization, Regional Office for Europe.

Dawson, J., L., L., Osman, G., L., Djamgoz, M., \& G. (2014). Management of cancer pain: 1. Wider implications of orthodox analgesiks. International Journal of General Medicine, 49. doi:10.2147/ijgm. s42187.

Delafuente, J. (2008). Pharmacokinetic and pharmacodynamic alterations in the geriatric patient. The Consultant Pharmacist $\AA, 23(4), 324-334$.

Departemen Kesehatan Republik Indonesia. (2006). Pedoman Pelayanan Farmasi (Tata Laksana Terapi Obat) untuk Pasien Geriatri. Jakarta: Direktorat Jendral Bina Kefarmasian dan Alat Kesehatan Departemen Kesehatan Republik Indonesia.

Dowell D, Haegerich TM, Chou R. CDC Guideline for Prescribing Opioids for Chronic Pain-United States. (2016). JAMA, 315(15), 1624-1645. doi:10.1001/ jama.2016.1464

Drug Interactions. (n.d.). website: http://www. micromedexsolutions.com/micromedex $2 / 4.34 .0 /$ WebHelp/Tools/Interactions/Drug_Interactions severity_definitions.htm.
Elumelu, TN. (2013). Palliative Care Experience in Breast and Uterine Cervical Cancer Patients in Ibadan, Nigeria. Journal of Palliative Care \& Medicine, 03(01). doi:10.4172/2165-7386.1000139.

Feng, X., Zhu, L., \& Zhou, Q. (2017). Opioid analgesiks-related pharmacokinetic drug interactions: From the perspectives of evidence based on randomized controlled trials and clinical risk management. Journal of Pain Research, Volume 10, 1225-1239. doi:10.2147/ jprs 138698.

Franconi, F., \& Campesi, I. (2014). Pharmacogenomics, pharmacokinetics and pharmacodynamics: interaction with biological differences between men and women. British Journal of Pharmacology, 171(3), 580594.

Jain, P., Pai, K., \& Chatterjee, A. (2015). The prevalence of severe pain, its etiopathological characteristics and treatment profile of patients referred to a tertiary cancer care pain clinic. Indian Journal of Palliative Care, 21(2), 148. doi:10.4103/0973-1075.156467.

Kementerian Kesehatan Republik Indonesia. (2017). Petunjuk Teknis Paliatif Kanker pada Dewasa. Jakarta: Kementerian Kesehatan Republik Indonesia.

Komite Farmasi dan Terapi RSKD. (2017). Formularium Rumah Sakit Kanker Dharmais. Jakarta: Komite Farmasi dan Terapi RSKD RS Kanker Dharmais.

Kotlinska-Lemieszek, A., Klepstad, P., \& Haugen, D. F. (2015). Clinically significant drug-drug interactions involving opioid analgesiks used for pain treatment in patients with cancer: A systematic review. Drug Design, Development and Therapy, 5255. doi:10.2147/ dddts 86983 .

Kuczynska, J. (2017). How should conversion from oral morphine to fentanyl patches be carried out?.19 Desember 2017. https://www.sps.nhs.uk/articles/howshould-conversionfrom-oral-morphine-to-fentanylpatches-be-carried-out/.

Leeuwen, R. V. (2012). Potential drug interactions among cancer patients using oral cytostatic drugs: a prevalence study. Http://isrctn.org/>. doi:10.1186/isrctn01739090.

Masman, A. D., van Dijk, M., Tibboel, D., Baar, F. P. M., \& Mathôt, R. A. A. (2015). Medication use during end-of-life care in a palliative care centre. International Journal of Clinical Pharmacy, 37(5), 767-775. http:// doi.org/10.1007/s11096-015-0094-3. 
McClay, H. (2010). Pain management in palliative care - choice of analgesia. Journal of the Malta College of Pharmacy Practice, (16), 28-31.

Moore, R. A., Derry, S., Aldington, D., Cole, P., \& Wiffen, P. J. (2015). Amitriptyline for neuropathic pain in adults. Cochrane Database of Systematic Reviews. doi:10.1002/14651858.cd008242.pub3.

Namazi, S., Kheshti, R., \& Aalipour, M. (2016). A comparison of five common drug-drug interaction software programs regarding accuracy and comprehensiveness. Journal of Research in Pharmacy Practice, 5(4), 257. doi:10.4103/2279-042x.192461.

Paice, J. A. and Ferrell, B. (2011), The management of cancer pain. CA: A Cancer Journal for Clinicians, 61: 157-182. doi:10.3322/caac.20112.

Panigoro, Sonar Soni. (2014). Rencana Strategis Pengembangan Pusat Kanker Nasional Indonesia, Sebuah Studi Kasus. http://journal.ui.ac.id/index.php/ arsi/article/viewFile/5207/3492.

Pieretti, S., Giannuario, A. D., Giovannandrea R. D., Marzoli, F., Piccaro, G., Minosi, P., Aloisi, A. M. (2016) Gender differences in pain and its relief. Ann 1st Super Sanita 52 (2), 184-189. doi: 10.4415/ANN_16_02_09.

Rana, S. P., Ahmed, A., Kumar, V., Chaudhary, P. K., Khurana, D., \& Mishra, S. (2011). Successful Management of a Difficult Cancer Pain Patient by Appropriate Adjuvant and Morphine Titration. Indian Journal of Palliative Care, 17(2), 162-165.

Rastogi, R., Swarm, R. A., \& Patel, T. A. (2011). Case Scenario: Opioid Association with Serotonin Syndrome. Anesthesiology, 1. doi:10.1097/aln.0b013e31823940c0.

Soldin, O. P., \& Mattison, D. R. (2009). Sex Differences in Pharmacokinetics and Pharmacodynamics. Clinical Pharmacokinetics, 48(3), 143-157. doi:10.2165/00003088200948030-00001.
Stockley, I. H. (2008). Stockleys drug interactions: a source book of interactions, their mechanisms, clinical importance, and management. London: Pharmaceutical Press.

Su, M. (2015). Amitriptyline Therapy in Chronic Pain. International Archives of Clinical Pharmacology, 1(1). doi:10.23937/2572-3987.1510001.

Truven Health Analytics. (2017). Micromedex Solutions: Drug Interactions. http://remotelib.ui.ac. id:2232/micromedex2/librarian/PFDefaultActionId/ evidencexpert. Show Drug Inter actions Results.

Turnheim, K. (2003). When drug therapy gets old: pharmacokinetics and pharmacodynamics in the elderly. Experimental gerontology, 38(8), 843-853.

Upadhyay, S., Jain, R., Chauhan, H., Gupta, D., Mishra, S., \& Bhatnagar, S. (2008). Oral Morphine Overdose in a Cancer Patient Antagonized by Prolonged Naloxone Infusion. American Journal of Hospice and Palliative Medicine $\AA$, 25(5), 401-405. doi:10.1177/1049909108319260.

Vincent, K., \& Tracey, I. (2008). Hormones and Their Interaction with the Pain Experience. Reviews in Pain, 2(2), 20-24. doi:10.1177/204946370800200206

Vizcaychipi, M. P. (2007). Serotonin Syndrome triggered by Tramadol. BJA: British Journal of Anaesthesia, 99 (ELetters Supplement). doi:10.1093/bja/el_2126

World Health Organization. (2014). Global Atlas of Palliative Care at the End of Life. Diambil dari http:// www.who.int/nmh/Global_Atlas_of_Palliative_Care. pdf 